\title{
IN-CORE INSTRUMENTATION TEST PROGRAM
}

BABCOCK \& WILCOX

Nuclear Power Generation Department

Power Generation Division P. O. Box 1260

Lymehbarg, Virginit 24505 


\section{DISCLAIMER}

This report was prepared as an account of work sponsored by an agency of the United States Government. Neither the United States Government nor any agency Thereof, nor any of their employees, makes any warranty, express or implied, or assumes any legal liability or responsibility for the accuracy, completeness, or usefulness of any information, apparatus, product, or process disclosed, or represents that its use would not infringe privately owned rights. Reference herein to any specific commercial product, process, or service by trade name, trademark, manufacturer, or otherwise does not necessarily constitute or imply its endorsement, recommendation, or favoring by the United States Government or any agency thereof. The views and opinions of authors expressed herein do not necessarily state or reflect those of the United States Government or any agency thereof. 


\section{DISCLAIMER}

Portions of this document may be illegible in electronic image products. Images are produced from the best available original document. 


\section{UNITED STATES \\ ATOMIC ENERGY COMMISSION \\ WASHINGTON, O.C. 20Bas}

FES $1 \&$ WrS

Mr. James F. Mallay

Manager, Lfcensing

Nuclear Power Generation

Babcock \& Wilcox Company

P. 0. Box 1260

Lynchburg. Virginfa 24505

Dear Mr. Mallay:

He have completed our review of your toptcal report, BAli-10001. dated August 1969, "Incore Instrumentation Test Progran." In

the context that the instrumentation is used only for physics calculation veriffcation and fuel management, we consider the report adequate. However, if credit for power flattening beyond the capability of the excore instrumentation becomes necessary, the detection characteristics of this systent would require further review.

\section{Sincerely,}

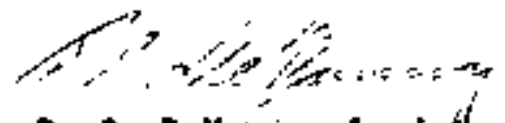

R. C. DeYoung, Asststátant Director for Pressurized Water Reactors otrectorate of Licensing 


\section{A.BSTRACT}

In-core flux monitors are used in Babcock \& Wilcox-designed central station power reactors to provide power distribution information to confirm phyaics calculations and to execute a fuel management program. To qualify the all-solid self-powered detector as an in-core monitoring device, $B \& W$ initiated several programe to qualify this device for the operating environment of a PWR. These programs included the following features:

1. Determination of the detector's basic physics characteristics.

2. Lifetime tests in a radiation environment.

3. Mechanical integrity tests of the detector and it's assembly.

Test results may be summarized as follows:

1. The electrical resiatance of the detectors does not change a a result of prolonged exposure.

2. The rhodium neutron gensitivity decreases predictably as a function of neutron exposure, and the depletion of sensitive material cán be accurately estimated without using external calibration devices. The detector is spectrum senaitive and can be computer compensated for variations in the flux spectrum. The background effects can be closely approximated for all axial positions by using a single background detector.

3. Reproducibility between detectorg can be controlled by manufacturing quality control procedures.

4. The all-solid detector is highly reliable; there was no fallure of any detector that met epecifications upon installation.

5. The ascembly developed for central station use permits tnanual insertion-withdrawal with only small forces, and without the use 
of lubricante. The asembly seal proved to be highly reliable and wat quickly inetalled.

6. Both computers and conventional picoammeter provide accurate readinge of the detector ontput.

7. There it no indication of lifotime limitation other than sensitivity lona renulting from neutron interaction. 


\section{CONTENTS}

1. INTRODUCTION

1.1. Background ........................ 1

1.2. General Design Requi remente .............. 2

2. IN-CORE MONITORNG SYSTEM DESIGN. . . . . . . . 3

2.1. Theory of Operation. . ................ 3

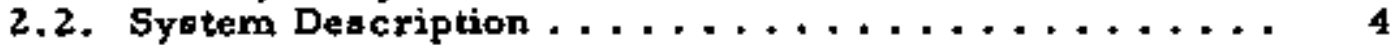

$2,2,1$, General ..................... 4

2.2.2. Calibration Techniques ............. 4

2.2.3. Detection and Control of Xenon Orcillations. . . 4

2.3. Operational Degign Banie ................ 5

2.3.1. Rhodium and Background Signal Strength . . . . 5

2.3.2. Detector Electrical Properties.......... 7

2.3.3. Rhodium Depletion Rate............. 7

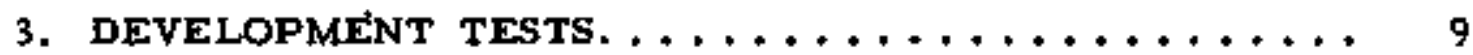

3, 1. Parametric and PWR Environment Tests........ 9

3.1.1, Test Core....................... 9

3.1.2. Effects of Shielding on Background Signal. ...99

3.1.3. Detector Responte Vertue Boron

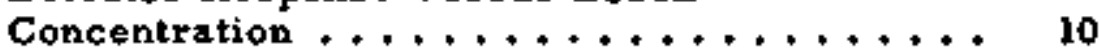

3, 1.4. Measurements With Activated Rhodium

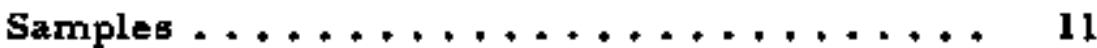

3. 1.5. Detector Signal Veruue Power Density ...... 12

3.2. Presaure Seal and Mechanical Insertion-

Wjthdrawal Mockup Tents................ 13

3.2.1. In-Core Instrumentation Preasure Soal

Testa ........................ 13

3.2.2. Mechanical Ineertion and Withdrawal Tests

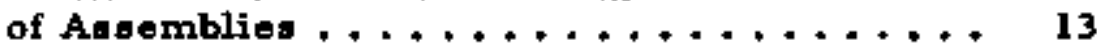

3. 3. Lifetime Irradiation Tests .................... 14

3. 3. 1. Babcock \& Wilcox Test Reactor (BAW TR) . . . . 15

3. 3.2, Big Rock Point (BRP) Reactor .......... 15

3, 3, 3, Lifetime Teats Evaluation ............. 15

4. SUMMARY AND CONCLUSION .................. 17

4, 1, Detector Lifetime ...................... 17

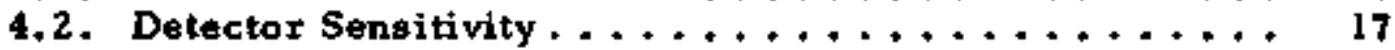

4.3, Reproducibility of Detector Capability. .......... 17

4. 4. As Bembly Derign. . ..................... 18

4.5. Conclusion ......................... 18 
Table

1. Central Station Stgnal Predictions ............. 6

2. Mechanical Insertion-Withdrawal Tests Sample Data,

In-Core Inatrumentation As \& emblie .......... 14

\section{Liet of Figuren}

Figure

1. Typical tn-Core Detector Locations. ............ 19

2. Typical In-Core Monitoring Channel ........... 20

3. Central Power Stetion - Predicted Flux Map With

Rhodium Detector Reeulte ................. 21

4. Shielding Arrangement ................... 22

5. Shielding Data Normalized ................ 23

6. Bare and Cadmium-Covered Sample Holder $\$ . . . . . .24$

7. Equilibrium Beta Emiagion Rate From 4.75-Inch-Long

Rhodium Wire Subjected to Unit $2200 \mathrm{~m} /$ : Thermal

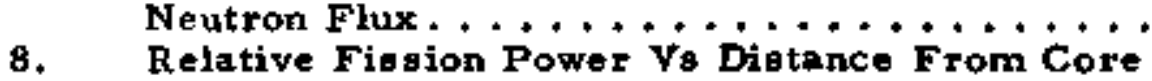

Bottom With $A_{g}-I n-C d$ Pins Withdrawn $0 \mathrm{~cm} . \ldots 26$

9. Relative Figeión Power Vs Diltance From Core

Bottom With Ag-In-Cd Pins Withdrawn $58 \mathrm{~cm} . \ldots 27$

10. Relative Finaton Power Va Diatance From Core

Bottom With Ag-In-Cd Pins Withdrawn $87 \mathrm{~cm} . . . . .28$

11. Relative Fiasion Power Va Diatance From Core

Bottom With Ag-In-Cd Pins Fully Withdrawn. . . . . . 29

12, Reactor Mockup ...................... 30

13. Big Rock Point Detector 5 Lifetime Test .......... 31

14. BAWTR Detector 7750 Lifetime Teat . . . . . . . . 32

15. Big Rock Point Detector Data With Wire Scan Curve $(3-20-67) \ldots \ldots \ldots 33$

16. Big Rock Point Detector Data With wire Scan Curve

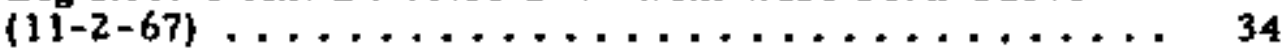

17. Big Rock Point Detector Data With Wire Scan Curve

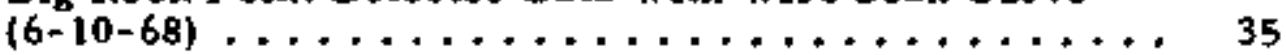

18. Big Rock Point Detector Data With Wire Scan Curve $(1-29-69) \ldots \ldots \ldots 36$ 


\section{INTRODUCTION}

\section{1. Background}

During 1962 and 1963 , B\&W conducted studieg of the in-core monitoring oystems that were being used in power reactors. Early in 1964, the development of the gelf-powered detector showed promise of fulfilling the need for an in-core monitoring detector in PWRs. However, many unknowns had to be investigated before the device could be adopted for commercial PWR use.

This report summarizes the development and testing to qualify the self-powered detector for pressurized water reactor service. B $\& W^{\prime} B$ test program investigated the basic physicg characteristics of the rhodium detector, the mechanical details of the in-core monitor ansembly. and the effects of long exposure to reactor environmental conditions. The major uncertainties of self-powered detectors related to use in PWRs before the development program were as follows:

1. Availability of detectors possessing the quality, and in the quantity, needed.

2. As-received reliability of detectors.

3. Relative sensitivity between two detectors.

4. Magnitude of interaction between detectors.

5. Magnitude and distrtbution of background radiation.

6. Effect of temperature on detectors.

7. Rate of rhodium depletion in neutron flux.

8. Rate of change of the detector's electrical properties with time and exposure.

9. Effect of the PWR lattice on results.

10. Relationship between detector signal (neutron flux) and local power in a PWR.

Except for the lifetime terting, all development work was per formed at B\&W's Critical Experiment Laboratory (CEL) in Lynchburg, 
Virginia. The longevity testa were performed at Consumers Power Company's Big Rack Point Reactor in Michigan, and at the Babcock \& Wilcox Test Reactor (BAWTR) in Lynchburg, Virginia.

\section{2. General Deaign Requirementa}

In evaluating an in-core monitoring system, the following design criteria were aet:

1. The in-core system thould monitor sufficient points to determine neutron flux and power conditions throughout the reactor core.

2. The device must measure local power within $\pm 10 \%$, and should preferably measure it within $\pm 5 \%$.

3. The device ahould measure local power with the required accuracy above $15 \%$ of rated power.

4. The in-core device should have a life expectancy of at least one year.

5. The in-core assembly must fit the amall core lattice of a PWR.

6. The in-core assembly must not interfere with refueling operations.

7. The in-core design should minimize the time required to remove the as prolongation of refueling perioda.

8. The in-core as tembly muet not interfere with rod drives on the reactor head.

9. The device must be economical.

Each of the design criteria has been met. The gystem is capable of measuring local power within $\pm 5 \%$, and the lifetime of the detector is several average full-power flux years. The assembly is small, easily retractable, and does not prolong refueling time. Sufficient assemblies are included to monitor power locally throughout the entire nuclear core. 


\section{IN-CORE MONITORING SYSTEM DESIGN}

\section{1. Theory of Operation}

Traditionally, neutron flux profiles are meadured in nuclear reactors of all types by activating wires inpile and subsequently counting them outpile. This practice is extended with the all-solid neutron detector, which allows continuous reading of a Begment of high-purity wire in place in the reactor. This is accomplished by isolating the senaitive wire (emitter) from the electrical ground and attaching a leadwire to it to allow measurement of the current (flow of electrons) into the wire to replace escaping beta particleg (see sketch below). The emitter material is rhodium. Because the rhodium in the emitter is depleted slowly by the neutron bombardment, the rate of depletion may be predicted with good accuracy.

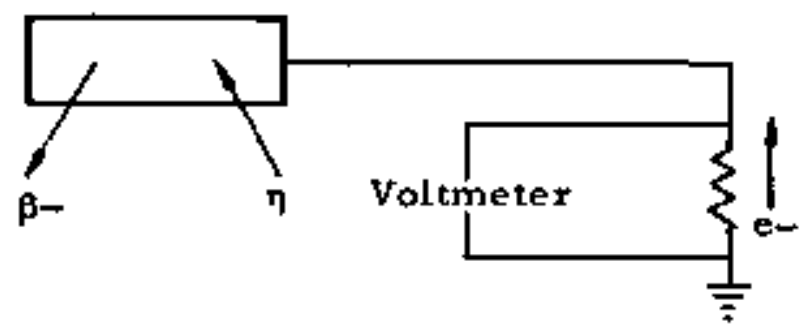

Since the neutron flux is measured only in the region occupied by the emitter (4 inches long), for PWR applications a number of detectors are bound together in an assembly (with emitter at different locations) to provide discrete data points that give axial power distribution.

Quite often, flux wire activation analysis is uncertain because of im purities in the wire sample. Since rhodium is a $99.5 \%$ pure metal. the se error are minimized. 
Some background effects occur in both the leadwire section of the detector a well as the rhodium section. Therefore, each assembly of detector s contains an emitterlesa (background) detector extending up through the core to the uppermost neutron detector. The signal from this detector is used to deduce the background correction factor for all neutron detector signals.

2. 2. System Description

\section{2. 1. General}

The basic in-core monitoring aystems for B\&W PWR $s$ comprise assemblies of self-powered neutron detector located at preselected position: within the core. An in-core monitoring arrangement is shown in Figure 1 an an example. An in-core detector asembly containing seven lacal fux detectors and one background detector, is installed in the instrumentation tube of each fuel assembly as obown in Figure 2. The local detectors are placed at different axial elevations to provide the axial flux gradient. The outputs of the local flux detector $\mathrm{s}$ are referenced to the background detector output, so that the differential signal is a true meagure of neutron flux. Readout for the in-core detectors is by the plant computer, but multipoint recorder readouta of selected detectors are provided independently.

When the reactor 15 depresaurized, the in-core detector aseembliea can be ingerted or withdrawn through quide tubes which originate at a shielded area in the reactor building (Figure 2). These guide tubes enter the botton head of the reactor veseel whe re internal guides extend up to the instrumentation tubes of the selected fuel assemblies. The instrumentation tube serves as a guide for the in-core detector assembly. During refueling operations, the in-core detector assemblies are withdrawn to allow free transfer of the fuel asgemblies. After the fuel assemblies are placed in their new locatione, the in-core detector assemblies are returned to their fully inserted positions.

\section{2. 2. Calibration Techniques}

Since the nature of the detectors permits the manufacture of nearly identical detectors, the relative accuracy between individual detectora can be controlled to a high degree. 
Initial calibration of the detectora is not required. The in-core aelf-powered detector are controlled to precie levelo of initial sensitivity by quality control during manufacture. The sensitivity of a detector changes ove $r$ ite lifetime because of detector burnup, control rod positions, fuel burnup, and the like. The detector signals are computer compensated continuously for burnup of the neutron-sensitive material. The results of experimental programs to determine the magnitude of these factors have been incorporated into calculations and will be used to correct the output of the in-core detectors. Operation of detectors in both power and test reactors has demonstrated that the compensation program, coupled with the initial sensitivity, provides detector readouts that are accurate enough to eliminate the need for a calibration system.

\subsection{Detection and Control of Xenon Oscillations}

Under power operating conditions, the in-core detector $B$ supply information to the operator in the control room, Each individual detector measures the neutron flux at ita locality and is used to determine the local power density. Individual power densities are then averaged and a peak-to-average power ratio is calculated. Upon initial installation, the self-powered detector is capable of meaturing the relative flux within $5 \%$ when uaed in conjunction with an adjacent background detector. The sensitivity of the detector will decrease with exposure to neutron flux owing to tranomutation of the emittex in the detector. However, the use of integrated current inventories should limit additional inaccuracies to $1 \%$ per year for the average flux conditions.

\section{3. Operational Design Baain}

2. 3. 1. Rhodium and Background Signal Strength

The operation of an in-core monitoring string in an assumed cosine-shaped flux at the beginning of life (BOL) of the asaerobly and in a possible condition near the end of life (EOL) is predicted in this section.

The rhodium aignal will vary with both axial and radial positions in the core. Figure 3 is a plot of the axial neutron flux (2200 $\mathrm{m} / \mathrm{s}$ ) shape that has been normalized to a 12-foot-high core and a peak 
Table 1. Central Station Signal Predictiona

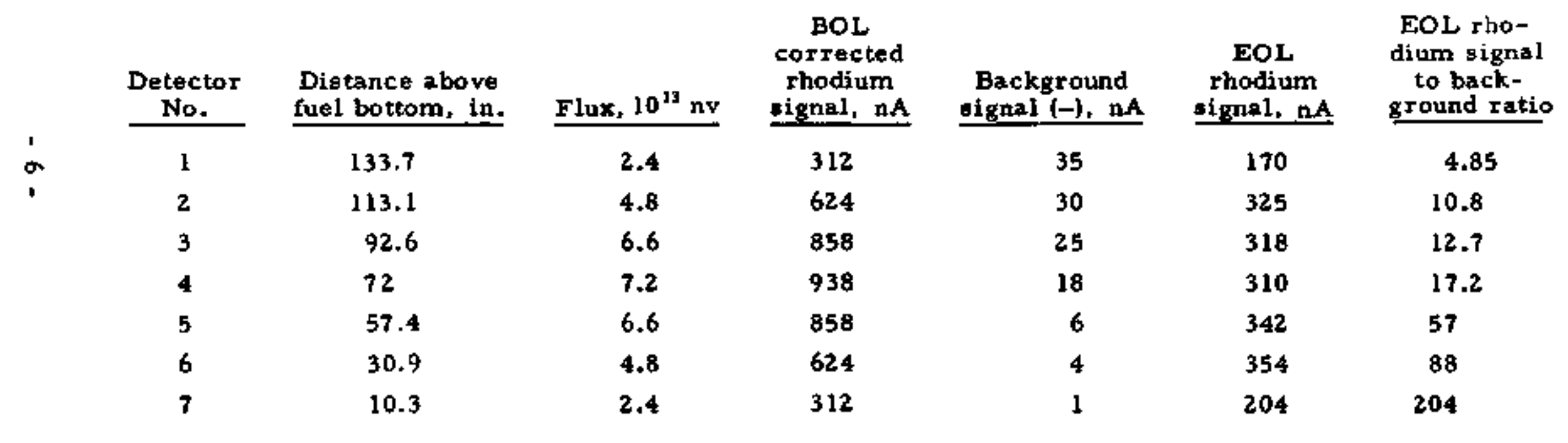


neutron flux value of $7.2 \times 10^{\mathrm{H}}$ nv, Table 1 list: nux values and calculated BOL and EOL output currente for each detector.

The curve in Figure 3 has been uned to predict background currents for ach detector listed in Table 1. Since the lead wirea extend from the bottom of the vessel, the top detectors have the highest background. For this prediction it has been astumed that the background is proportional to the area under the neutron flux curve. The highest background aignal for the total core length bas been calculated to be about $-35 \mathrm{nA}$.

\section{3. 2. Detector Electrical Properties}

To operate with a readout impedance of $10^{\circ}$ ohm 8 , the detector's insulation resiatance must be significantly larger than $10^{\circ}$ ohms. A typical detector with an insulation resistance of $10^{\circ} \mathrm{ohms}$, at environmental conditions of flux and temperature, would conetitute an acceptable leakage resistance, and any leakage current from the detector would be negligible. Analysis of the tent data indicates that there will be no degradation of the detector's insulation resintance for exponurea up to five average flux yearis.

\section{3. 3. Rhodium Depletion Rate}

The detector's lifetime is primarily a function of the rhodium depletion rate. The depletion rate is directly proportional to the expended current, and calibration during the detector lifetime is dependent on the current inventory.

The error for the best estimate of the total charge available is currently 2 to $3 \%$. When this uncertainty to applied to the deple. tion formula,

$$
S(t)=s(0)\left[1-\frac{Q(t)}{Q(\infty)}\right]
$$

where

$$
\begin{aligned}
& S(t)=\text { aenoitivity at time, } t \\
& S(0)=\text { initial densitivity } \\
& Q(t)=\text { charge consumed up to time, } \\
& Q(\infty)=\text { initial charge avallable }
\end{aligned}
$$


the resultant uncertainty in $s(t)$ is 2 to $3 \%$ when $\frac{Q(t)}{Q(\infty)}$ is 0.5 . Thus, if no refinements were made in the preaent model, the uncertainty due to rhodium depletion would be 3 to $5 \%$ at $60 \%$ depletion, $1 . e \cdot,\left(\frac{Q(t)}{Q(\infty)}=0.4\right)$. The average detector will reach this depletion after about 60 months.

The peak flux $\left(7.2 \times 10^{13} \mathrm{nv}\right)$ thown on Figure 3 represents an extreme, vince the peak flux would not remain at the wams location throughout the detector' $s$ lifetime. The average flux $(4.2 \times$ $10^{13} \mathrm{nv}$ ) represents a better picture of detector lifetime. It appears that acoemblies could serve for five years on the average. Arsemblies in the higher flux regions of the core will be replaced more frequently and near the edge of the core considerably less frequently. 


\section{DEVELOPMENT TESTS}

\section{1. Parametric and PWR Environment Tests}

During the "proof of principle" tests it became evident that additional information on the activation and properties of the rhodium detector would be required before solf-powered neutron detectors could be utilized. The refore, B\&W initiated, and is continuing, a development program to investigate the elf-powered detector for PWR upe.

\subsubsection{Test Core}

To simulate PWR applications, the properties of rhodium were measured in a water-moderated critical assembly with configurations that provided realiatic neutron environment. The parameter. of the cores in which measurements were made are typical of those used in water-moderated power reactors. The unperturbed bagic lattice contained $0.475-i n c h$-OD fuel rods with $2.46 \%$ entiched $\mathrm{UO}_{2}$, and the lattice pitch was 0.644 inch.

\section{1.2. Eifects of Shielding on Background Signal}

The atomic particles origisating outside the detector can contribute to the background aignal. Measurements of the background detector response verisus the total absorber thicknese between the oxide fuel and the detector were therefore undertaken to determine the magnitude of the background signal produced by beta particles originating from fission product decay within the oxide fuel and to determine the minimum shielding required to eliminate it.

Except for one measurement, the shielding data were taken with the arrangement shown in Figure 4. The 3/4-inch-diameter aluminum tube shown in the figure was located along the core axis and traverged the entire core. The total absorber thicknes $\mathrm{B}$ Burrounding the background detector was varied by interchanging various sizes of type321 stainlese ateel and Zircaloy-4 tubing. In some cases, the intervening 
space was filled with the borated moderator. The aingle measurement with a different shielding geometry was designed to bring the detector and a fuel rod as close together as was physically poseible. For the measurement, the detector wan taped to a fuel rod that replaced the 3/4inch-diameter aluminum tube in the center of the lattice.

The results are presented in Figure 5. The data fall into several groups depending on the type of shield material adjacent to the detector. Although there is gome signal attenuation with increased absorber thickness, the dominant signal variation clearly results from changes in the detector environment. This suggests that signal variations result mainly from charged particlea originating in the ahield material. Both gamma and neutron-induced reactione reault in the production of energetic charged particles. principally by the processes of photoelectric emission, Compton scattering, pair production, and beta emiesion following neutron activation. Since these measurements were made for irradiation times much shorter than the half-lives of most potential activation products, it is unlikely that the latter process is responsible. althuugh it might be significant for long-te $\mathrm{cm}$ reactor operation.

A more probable explanation is that the observed signal variation resulta from photoelectric and Compton electron effects (pair production effects presumed to cancell. The photoelectric and Compton scattering cross a ections of the shielding materials ued appear to be or sufficient magnitude to produce the observed aignal variation, and the correction would be in the direction to reduce the obeerved eignal variation.

3.1.3. Detector Responae Veruue Boron Concentration

The net (background corrected) equilibrium detector sigmal was measured in five clean critical lattices. Boron concentrations in the moderator-coolant ranged from 0 to 1500 ppm. All measurements were made at midcore height in a center water hole created by removing a fuel rod and allowing the resulting space to fill with moderator. To facilitate positioning of the detector, an open-ended, 0.439-inchdiameter by 0.036 -inch-wall aluminum tube was mounted along the core axis in the center water hole. The detector was centered inside the aluminum tube with Teflon spacera. 
In a power reactor inatallation, the detector fignal can be measured with a standard nanoammeter or picoammeter. However, the very amall currenta produced in the low-power critical assembly required the use of a more sensitive instrument. An electrometer wat employed, and the total charge produced by a given critical asembly operation was measured. The equilibrium current wes calculated from the charge.

The 2200-meter-per-econd neutron flux $\left(\phi_{0}\right)$ was meaoured with bare and cadmium-covered dysprobium-aluminum wires. The wires were loaded into a sample holder, illustrated in Figure 6, and positioned at precisely the oame location as that of the rhodium element of the detector. Small corrections $(w 1 \%)$ were made to account for a slight deviation of the dysprosium absorption cross section from $1 / \mathrm{V}$ behavior in the thermal region.

The final ratios have an estimated random uncertainty of $1.5 \%$ and a aystematic error of $4.2 \%$. Within statistics, the net detector aignal (S), in ampg, produced by a unit thermal flux $\left(\phi_{0}\right)$, in $\mathrm{n} / \mathrm{a}-\mathrm{cm}^{2}$, does not vary over the range of neutron epectra involved. The relationship between $\phi_{0}$ and the net signal (S) from a detector located in the asymptotic neutron spectrum region of any of the five lattices studied may be expresoed by the equation

$$
\mathbf{S}=\mathbf{K} \boldsymbol{\phi}_{0} \mathbf{R} / \mathbf{R}-\mathbf{1}
$$

where $\mathrm{K}$ is detector Bensitivity and $\mathrm{R}$ the cadmium ratio of the rhodiun element.

\section{1.4. Measurements With Activated Rhodium Samples}

Since the principal signal from the neutron flux monitor under atudy resulte from the beta decay of activated rhodium wire, many of the basic parametere aseociated with the detector can be determined by analyzing the decay of rhodium amples that have been activated in a known neutron flux. Parameters obtained by this approach include:

1. K (in equation 1) for a 4.75-inch-long element.

2. The effective $2200 \mathrm{~m} / \mathrm{a}$ capture cross Bection ( $\Sigma$ th) of rhodium wire versus diameter. 
3. The probability (P) versus diameter that a beta particle born in a rhodium wire will escape from the wire.

4. The half-life of ${ }^{10} \mathrm{Rh}^{\mathrm{m}}$.

5. The half-life of ${ }^{104} \mathrm{Rh}$.

The beta emistion rate (B) from an activated rhodium sample can be expressed as the sum of two exponentials following irradiation:

$$
B=I_{1} e^{-\lambda_{1} t_{w}}+I_{2} e^{-\lambda_{2} t} w
$$

When the beta decay of an irradiated sample was fit by least squares to equation 2 , half-jife values of ${ }^{104} \mathrm{Rh}^{\mathrm{m}}$ and ${ }^{104} \mathrm{Rh}$ were obtained from the fitting constants $\lambda_{1}$, and $\lambda_{2}$. The detector senaitivity Kas obtained from the fitting constants $I_{1}$ and $I_{2}$ and a measurement of the $2200 \mathrm{~m} / \mathrm{s}$ the rmal neutron flux $\left(\phi_{0}\right)$. The beta escape probability was determined by beta and gamma counting the ${ }^{104} \mathrm{Rh}$ isotope in identical activated rhodium samples. Thue the beta-to-gamma count rate ratio was directly proportional to the beta eacape probability (P). The proportionality constant was evaluated by beta and gamma counting a 0.0001 -inch-thick activated rhodium foil for which $P$ wag unity.

Measurements of the type described were made with bare and cadmium-covered rhodium wire 10,20 , and $30 \mathrm{mils}$ in diameter. $K$ (equilibrium beta emisgion) was measured for the different rhodium wire diameters (Figure 7). Comparison of $K$ above with the more accurately measured shodium type monitor bensitivity showed agreement within experimencal error limitations.

\subsubsection{Detector Signal Versug Power Density}

Measurements relating net detector sigaal and power density in an adjacent fuel rod were made in a critical assembly mockup of a fuel aubasembly. The subassembly, 15 lattice pitches aquare, was located in the center of the critical assembly and was eparated from the remainder of the core by artificial boundaries. Within the subassembly, a cluster of 17 water holes, created by removing fuel rods and allowing the resultant wpace to fill with moderator. mocked up an instrument hold and a cluster of 16 withdrawn control rods, In other gimilar 
measurements, 0.400 -inch-OD Ag-In-Cd poivon pine 179.7 wt $\%$ Ag, 15.1 wt \% In, and 5.1 wt \% Cd) were inserted into the water holes to mock up a partially ingerted or fully incerted control rod cluster.

Axial traversee of the net detector signal were determined for a variety of control rod cluster insertion depthe. Detector positioning was as previously described. The relative power distribution along the length of an adjacent fuel rod was measured by counting collimated fission product decay gammas from the activated fuel rod. These meagurements were then normalized to absolute values of fission density based on the ${ }^{99}$ Mo content of irradiated fuel amples.

Correlation between the net detector signal and the fission density profile of the adjacent fuel rod is presented in Figurea 8 through 11. The net detector signal (in unita of amperes) has been scaled up by a factor of $1.75 \times 10^{18}$. To facilitate comparison, fistion density determinations by fuel rod scanning have also been averaged over the 4-inch spans corresponding to the axial position of the sensitive portion of the detector.

\subsection{Preasure Seal and Mechanical Invertion-} Withdrawal Mockup Terts

\subsubsection{In-Core Instrumentation Preagure Seal Tests}

Seal tests were conducted at pressures exceeding the reactor vessel hydrostatic test pressure (3125 paig) and at temperatures from 70 to $180 \mathrm{~F}$. The final preseure seal ascembly design employing two silver-coated $O$-rings was tested at pressures exceeding 3650 psig and temperature cycles up to $180 \mathrm{~F}$ with no vibible leakage.

\section{2. 2. Mechanical Insertion and Withdrawal} Testr of ABgemblies

In-core inst rumentation asemblies are inserted and withdrawn witbin the in-core monitoring ayatem piping during reactor refueling operations. The in-core monitoring system piping, which is between 100 and 130 feet long, has two 90 degree turns. Mechanical insertion and withdrawal tests were conducted on different types of incare instrumentation assemblies to ensure that insertion-withdrawal forces do not exceed practical manual handling capabilitied. The atsemblies were inserted in a mockup of the in-core monitoring system 
piping (see Figure 12), and ineertion and withdrawal force were measured. Table 2 list typical forces required for the inuertion-withdrawal cycles.

Table 2. Mechanical Intertion-Withdrawal Teats Sample Dita, In-Core Inetrumentation Assemblies

(Average Force in Pound,)

\begin{tabular}{|c|c|c|}
\hline $\begin{array}{c}\text { Distafnce, } \\
\text { feet }\end{array}$ & Eneertion & Withdrawa \\
\hline $70-75$ & $7-1 / 2$ & 7 \\
\hline $75-80$ & 7 & 7 \\
\hline $80-85$ & 8 & 7 \\
\hline $85-90$ & 9 & 9 \\
\hline $90+95$ & 17 & 13 \\
\hline $95 \cdot 100$ & 24 & $14-1 / 2$ \\
\hline $100-102$ & 27 & $13-1 / 2$ \\
\hline
\end{tabular}

(a) The force required to insert and withdraw in-core instrumentation asembly from 0 to 70 feet was only the weight of the as6emby.

\section{3. Lifotime Irradiation Tests}

One of the original objectives of the test program was to provide a self-powered detector that would have a minimum lifetime of three years. Arrangements were made with Consumers Power Company to test an atsembly of these detectore in the Big Rock Point Reactor in Michigan. To provide an independent check, a second assembly was teated in the BAWTR in Lynchburs, Both ansemblies are still operating and warking well at the time of publication of this report. Detectors in the Big Rock Point Reactor have exceeded a five-year average-flux lifetime, and those in the BAWTR have exceeded a three-year average-flux lifetime. These longevity tests indicate that there has been no degradation 
in the basic detector and that the rhodium depletion rate, through neutron interactions, is the only limiting factor in the detector's lifetime.

3. 3.1. Babcock \& Wilcox Teat Reactor (BAWTR)

The all-eolid (aelf-powered) detector being tested at the BAWTR include six rhodium detector and four background detectors. The tegt environment is a thermal flux of $\mathrm{a} \times 10^{13} \mathrm{nv}$. Proviaions are available to alter the temperature between 300 and $800 \mathrm{~F}$. The basic resdout device for the BAWTR test program is the Bailey Meter Company 750 data logging aystem. This system and the associated instrumentation aystems monitor, record, and stors all esential test data for information processing.

\section{3.2. Big Rock Point (BRP) Reactor}

The Big Rock Point detectors include six rhodium and three background detectors. The maximum test environmental conditions are a thermal flux of approximately $1 \times 10^{14} \mathrm{nv}$, and, an environmental temperature of $575 \mathrm{~F}$. Besides conventional test instrumentation, a computer+system processes BRP lifetime test data. Figure 13 showe a typical rhodium detector depletion curve compiled by the test. inetrumentation.

\section{3. 3. Lifetime Tests Evaluation}

The tests at BRP and the BAWTR have indicated the lifetime characteriatics of the detectore. They have also established that signal noise from industrial plant operating machinery is not induced in the cabling. The reproducibility of measurements made at the BAWTR is superior, as shown by the low scatter in date obtained during the lifetime testa (Figure 14), since flux valued were verified by laboratory equipment. The verification had to be made by wire activation analyais, which has a wide tolerance in accuracy because of wire impurities and other factora. The BAWTR tests established that the available initial charge of the installed detectors varied within $\pm 4 \%$.

Figures 15 through 18 present typical data obtained during various stages of the BRP test program. These sigures compare data with the wire map data taken early in the program. As ahown, the incore detector data retains the ghape of the wire scan even though slighty 
depressed because of depletion of the rhodium-sensitive material. Figure 18 presente typical data taken early in 1969. At this atage there was conside rable depletion of the rhodium, but the depletion-available charge curve (Figure 13) could otill be used to reestablish the actual flux. 


\section{SUMMARY AND CONCLUSION}

\section{1. Detector Lifetime}

The self-powered detectors have been exponed to reactor environments exceeding a five-year average full power (850 MWt) flux lifetime. The electrical leakage resistance has whown no signe of degradation with time. The lowest resistance has remained about $10^{9}$ ohms. The rhodium is more than $60 \%$ depleted in the detector with the greatest huence. The rhodium depletion rate curve is mathematically well defined and can be used to predict the detectora' remaining aenuitivity. 4. 2. Detector Sensitivity

Average aensitivity of the detector is $1.3 \times 10^{-20} \mathrm{~A} / \mathrm{nv}$. Somo sensitivity variations do occur based on the changing energy epectrum within the core due to changes in moderator chemietry, fuel burnout, control rod positions, and reactor environment. Thene effecte are known and can be computer-compensated to determine the power diatribution. Relative power distribution within the core can be determined by the in-core detector to an estimated accuracy of $\pm 5 \%$ above $15 \%$ rated reactor power.

\subsection{Reproducibility of Detector Capability}

The reproducibility between detectors is maintained within $\pm 1 \%$ by careful quality control during manufacture. The all-oolid detector is dimply constructed of high-purity concentric componente, permitting precise tolerances to be imposed during manufacture to yield a highly reliable device. No detector that has pas sed the quality control requiremente has failed during a prolonged irradiation test in a reactor environment. 


\subsection{Assembly Design}

An in-core monitoring anembly including seven self-powered detectors and a background detector has been developed. The assembly is eatily inserted or withdrawn during refueling operations without the use of lubricants and without prolongling the refueling operation. The mechanical preaure oeal is highly reliable and quickly inotalled.

\section{5. Concluaion}

The all-solid aelf-powered detector is a reliable in-core monitaring device which can be ueed in PWR eervice to yield accurate core power dietribution data. 
Figure 1. Typical In-Core Detector Locations
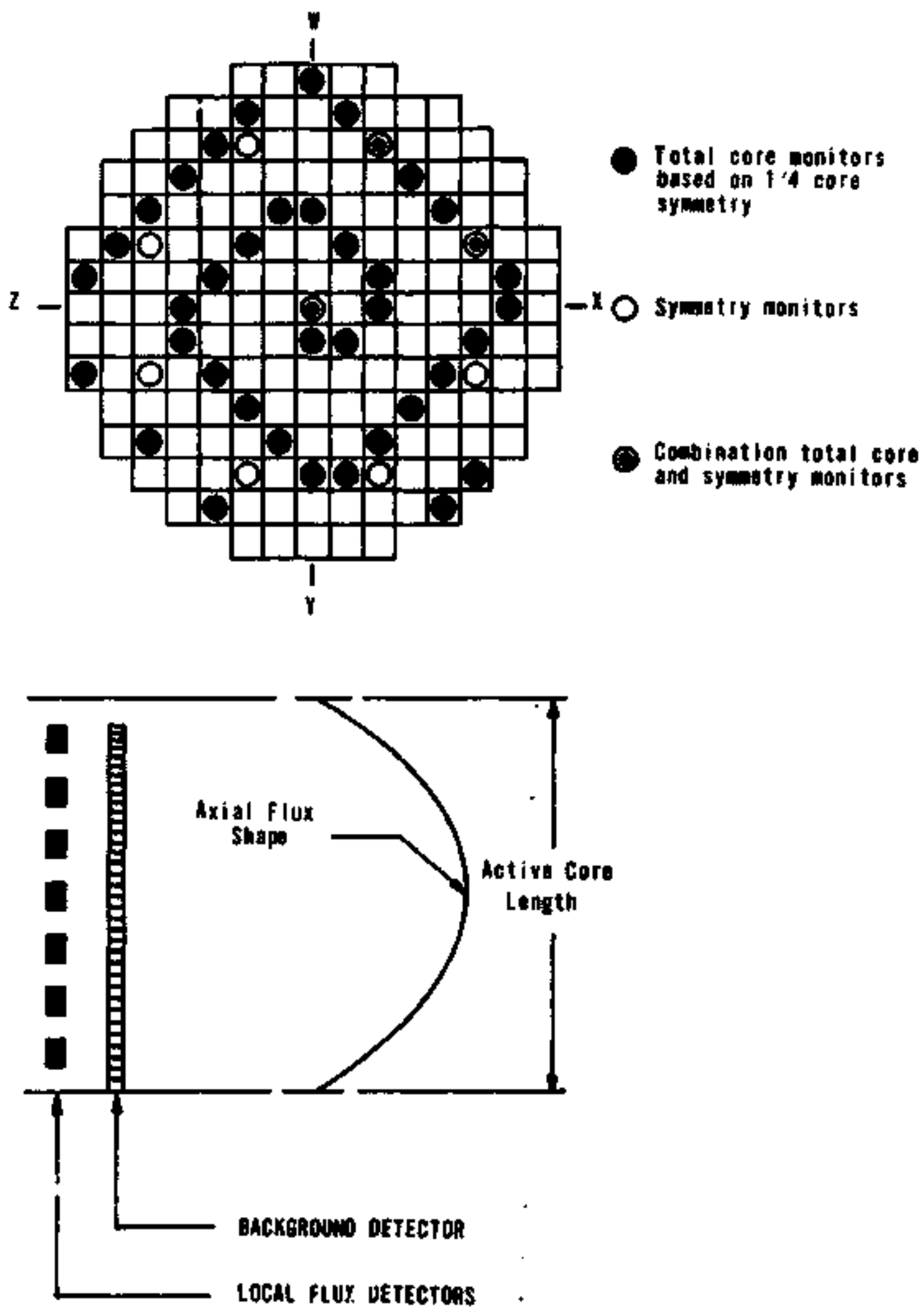
Figure 2. Typical In-Core Monitoring Channel

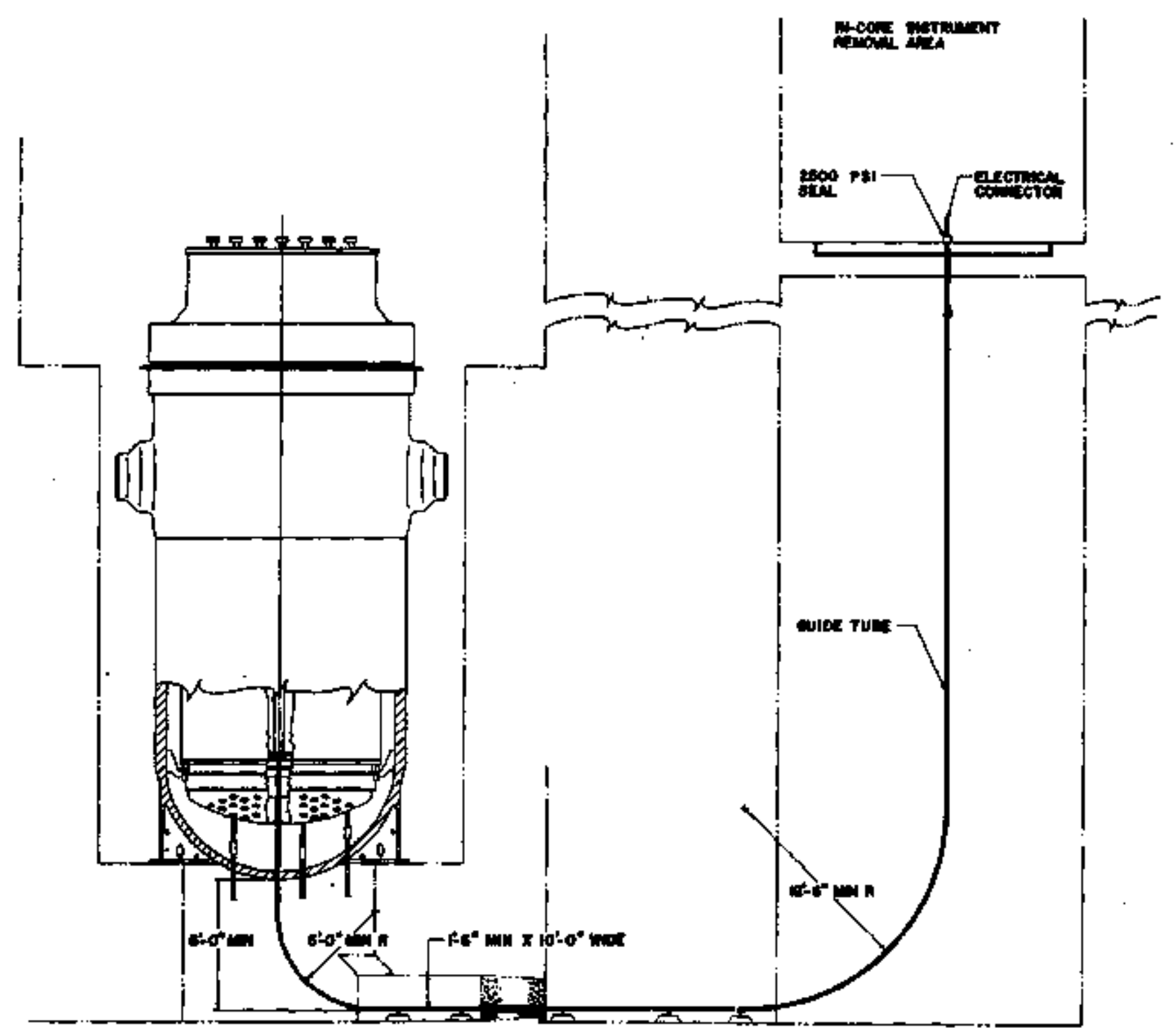


Figure 3. Central Fower Station -Predicted Flux Map With Rhodium Detector Results

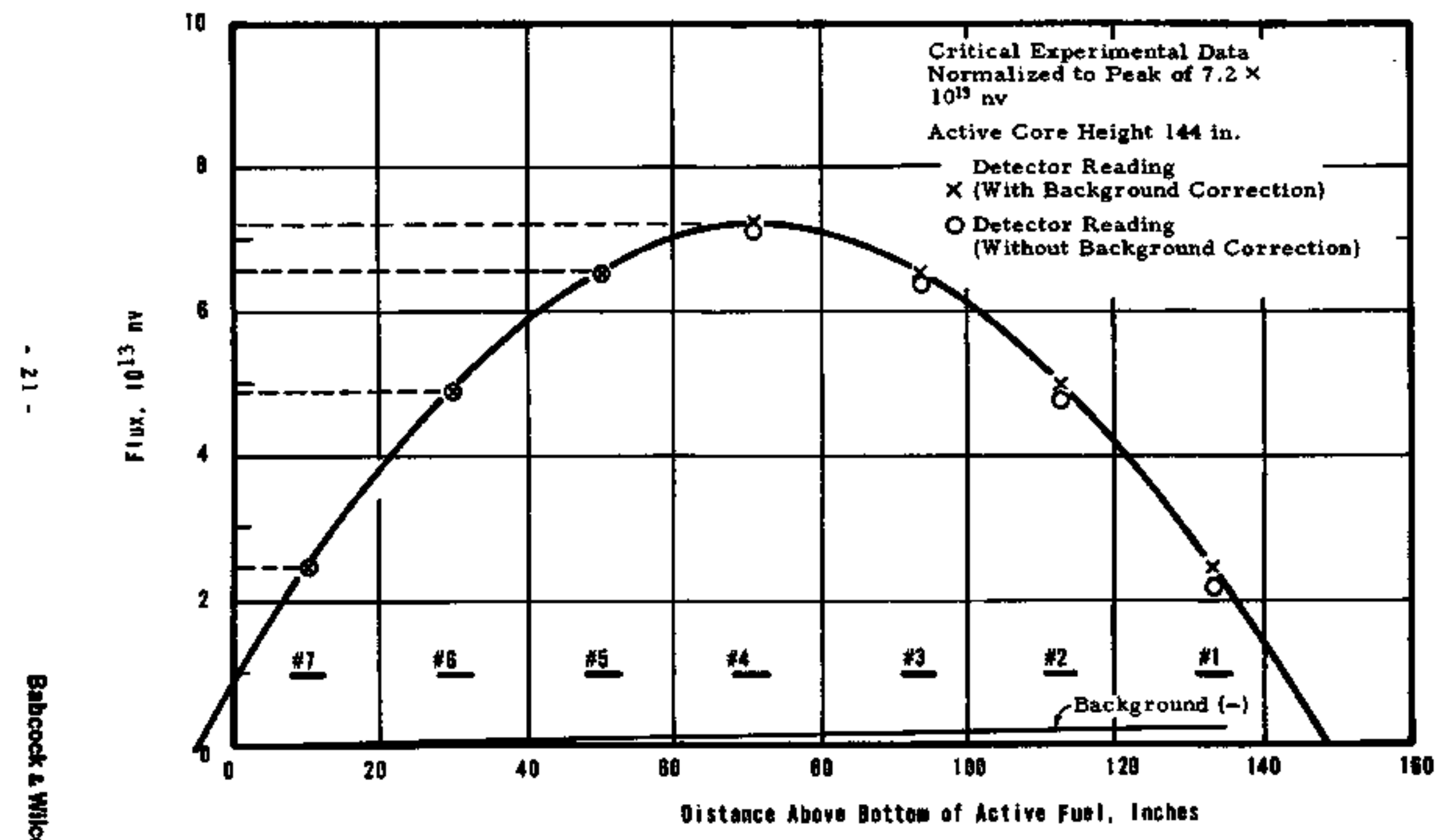


Figure 4. Shtelding Arrangement

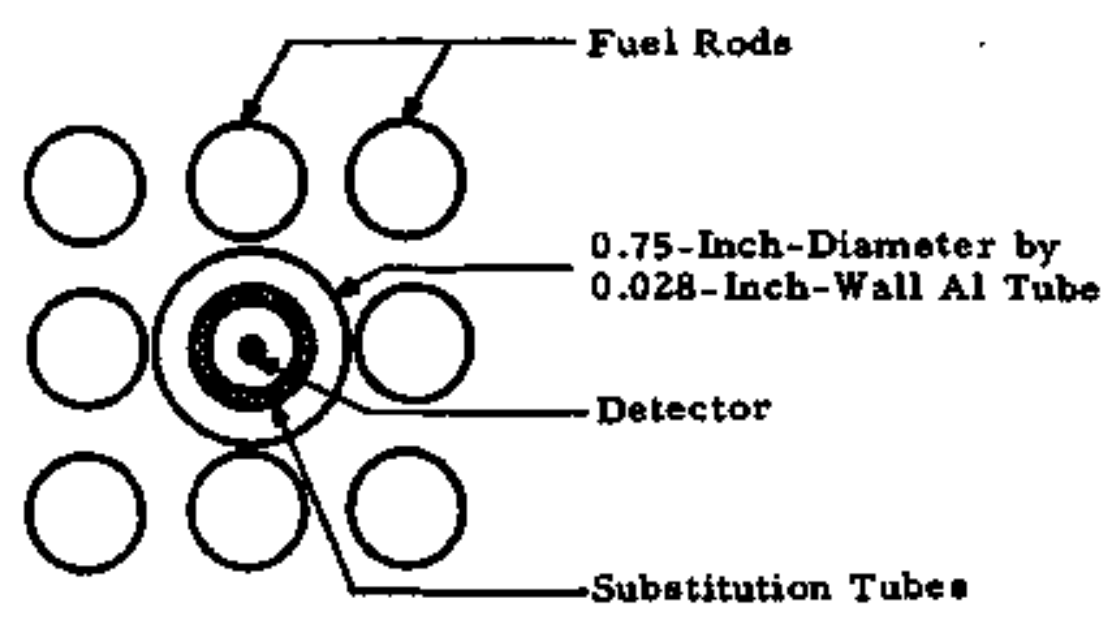


Figure 5. Shielding Data Normalized

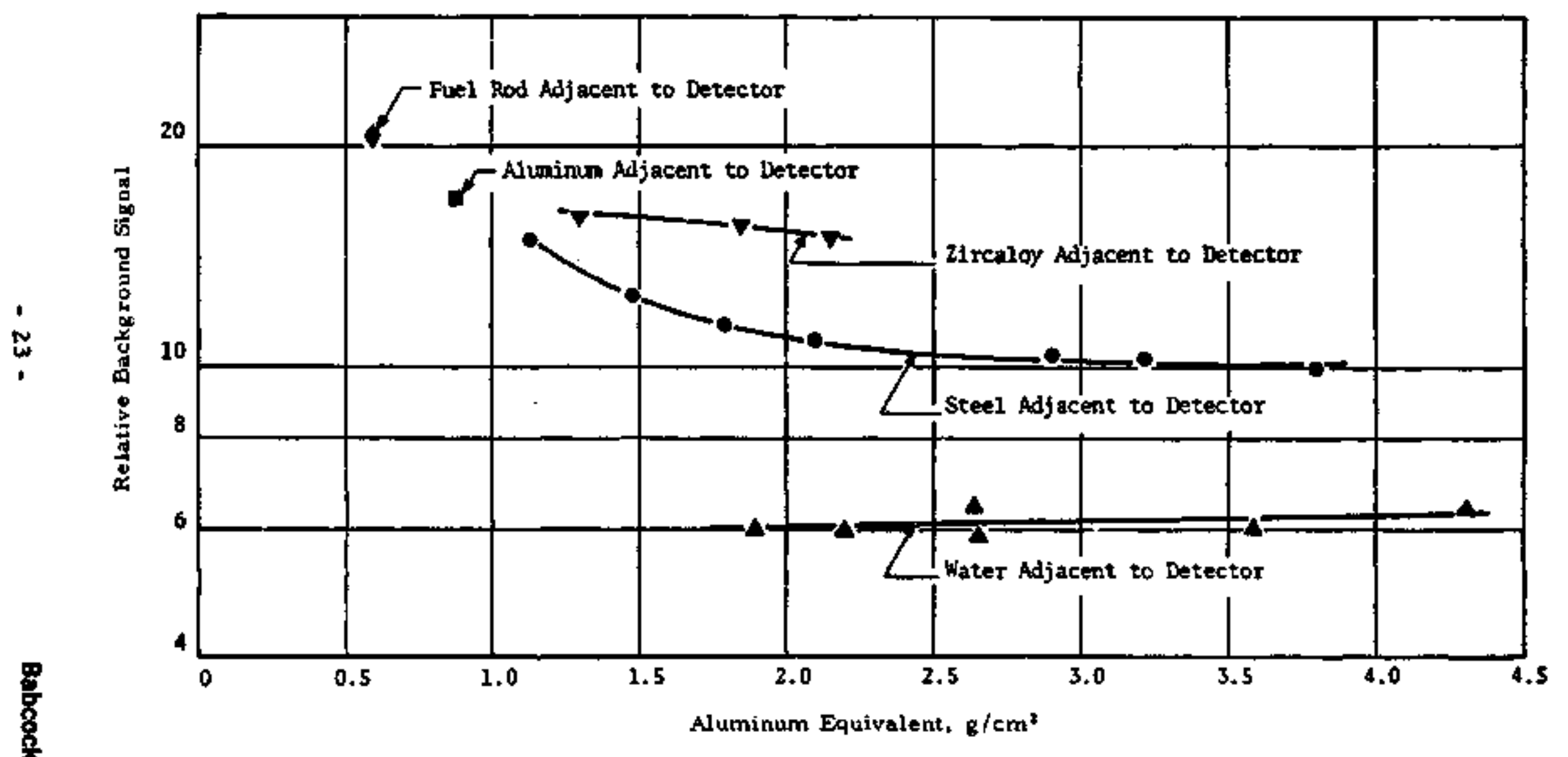


Figure 6. Bare and Cadmium-Covered Sample Holder.

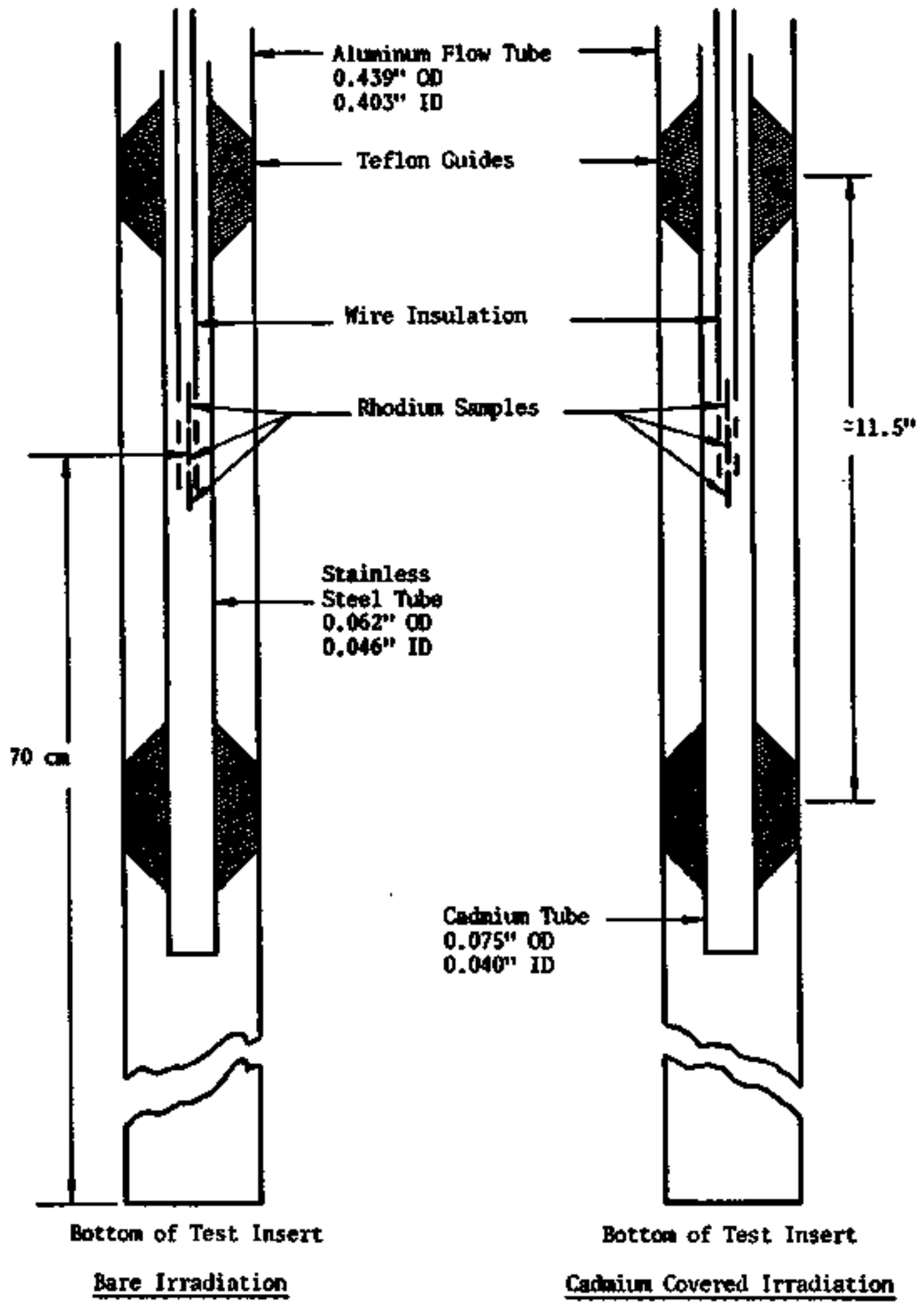


Figure 7. Equilibrium Beta Emisoion Rite From 4.75-Inch-Long Rhodium Wire Subjected to Unit $2200 \mathrm{~m} /$. The rmal Neutron Flux

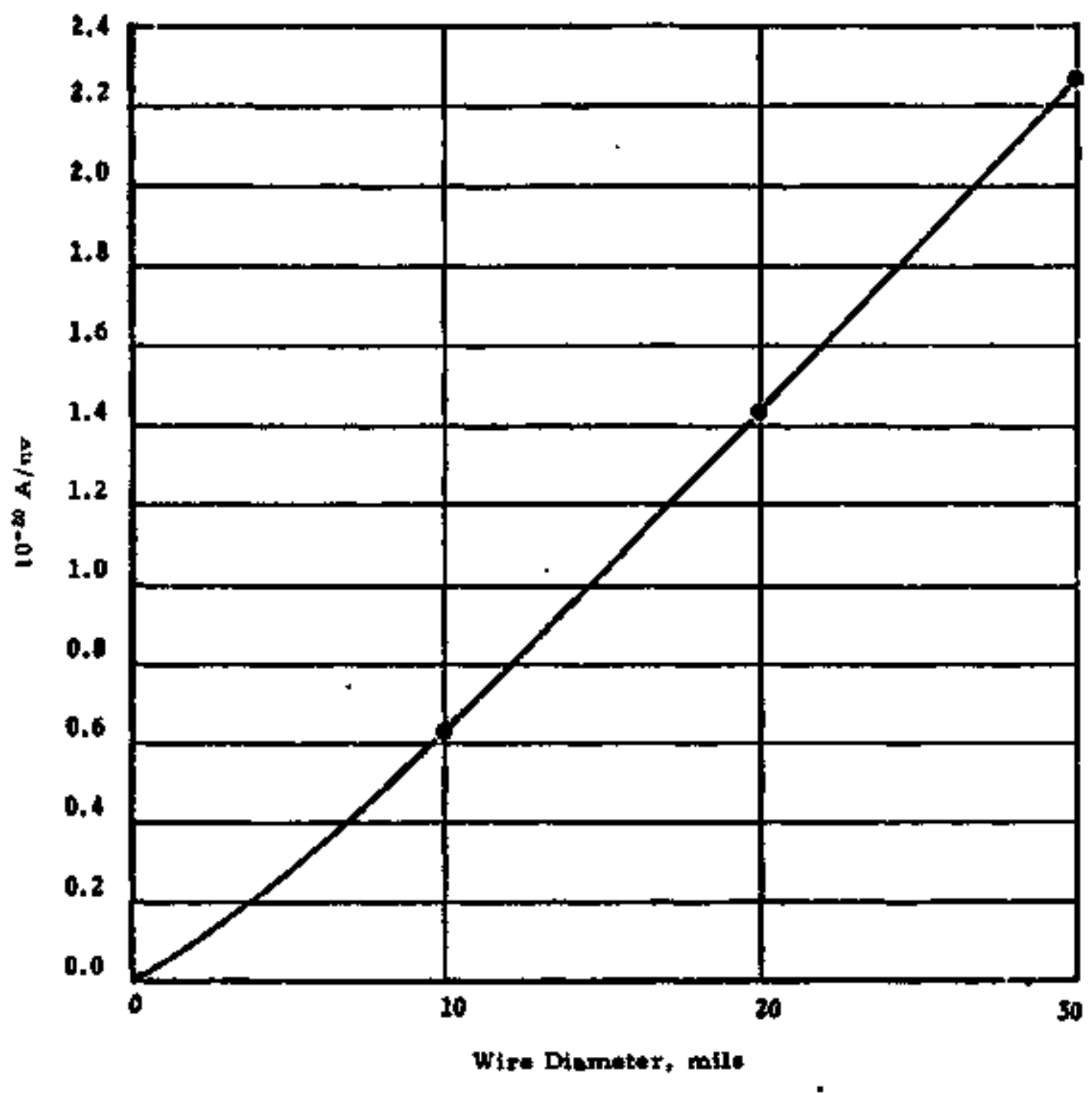


Figure 8. Relative Fission Power V. Dietance From Core Bottom With As-In-Cd Pins Withdrawn $0 \mathrm{~cm}$

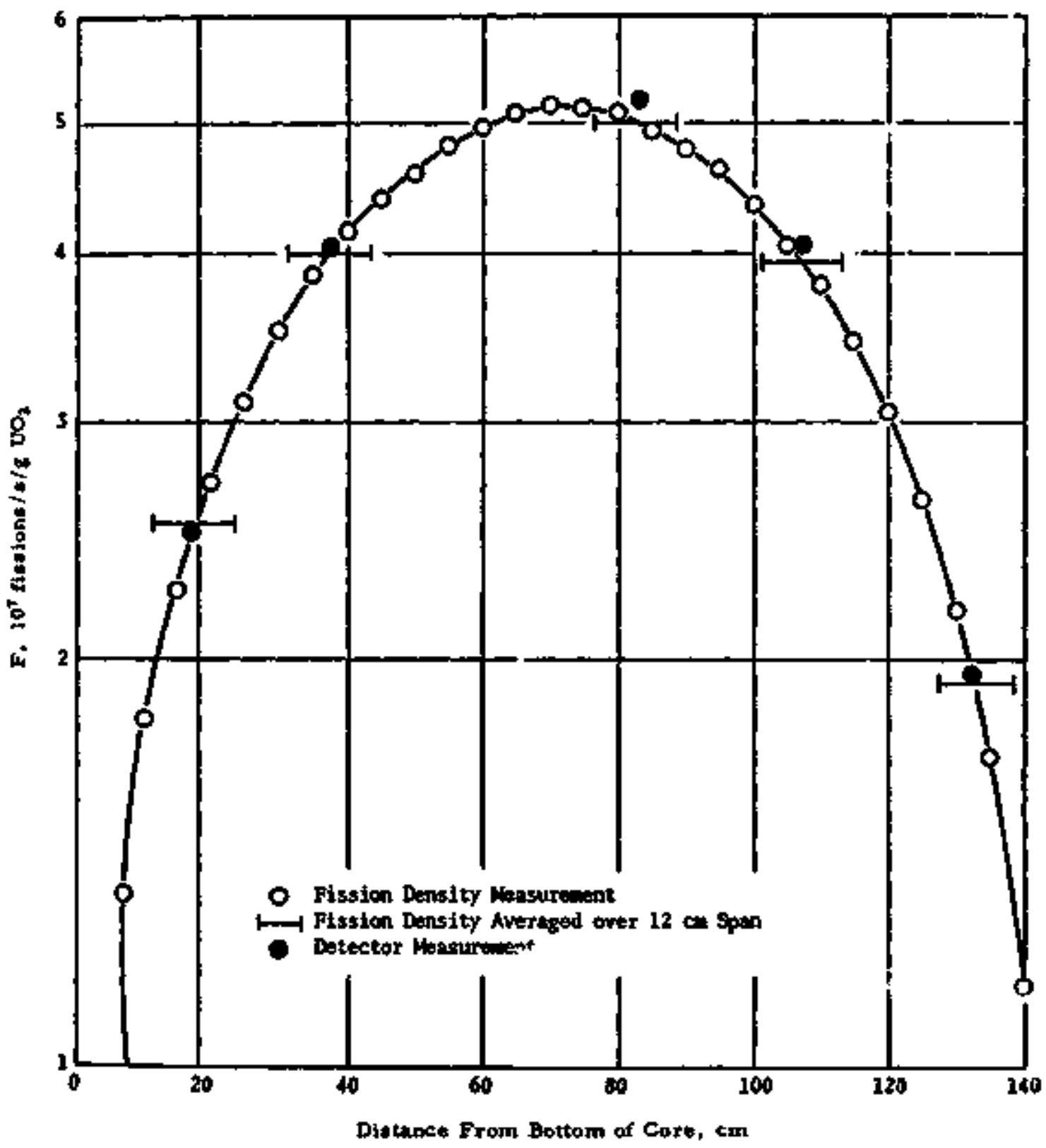


Figure 9. Relative Fission Power Va Distance From Core Bottom With Ag-In-Cd Pine Withdrawn $58 \mathrm{~cm}$

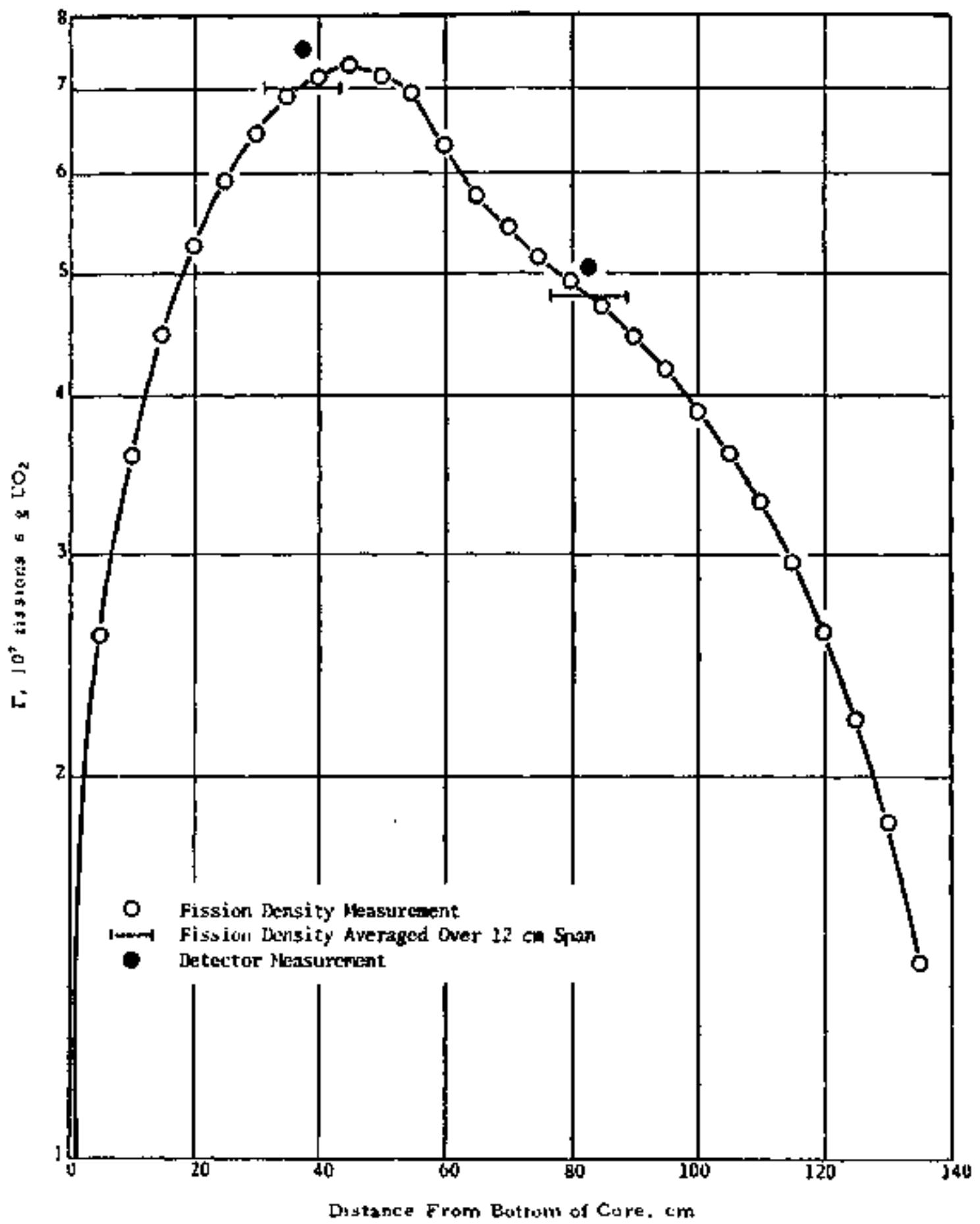


Figure 10. Relative Fission Power Va Dietance From Core Bottom With As-In-Cd Pins Withdrawn $87 \mathrm{~cm}$

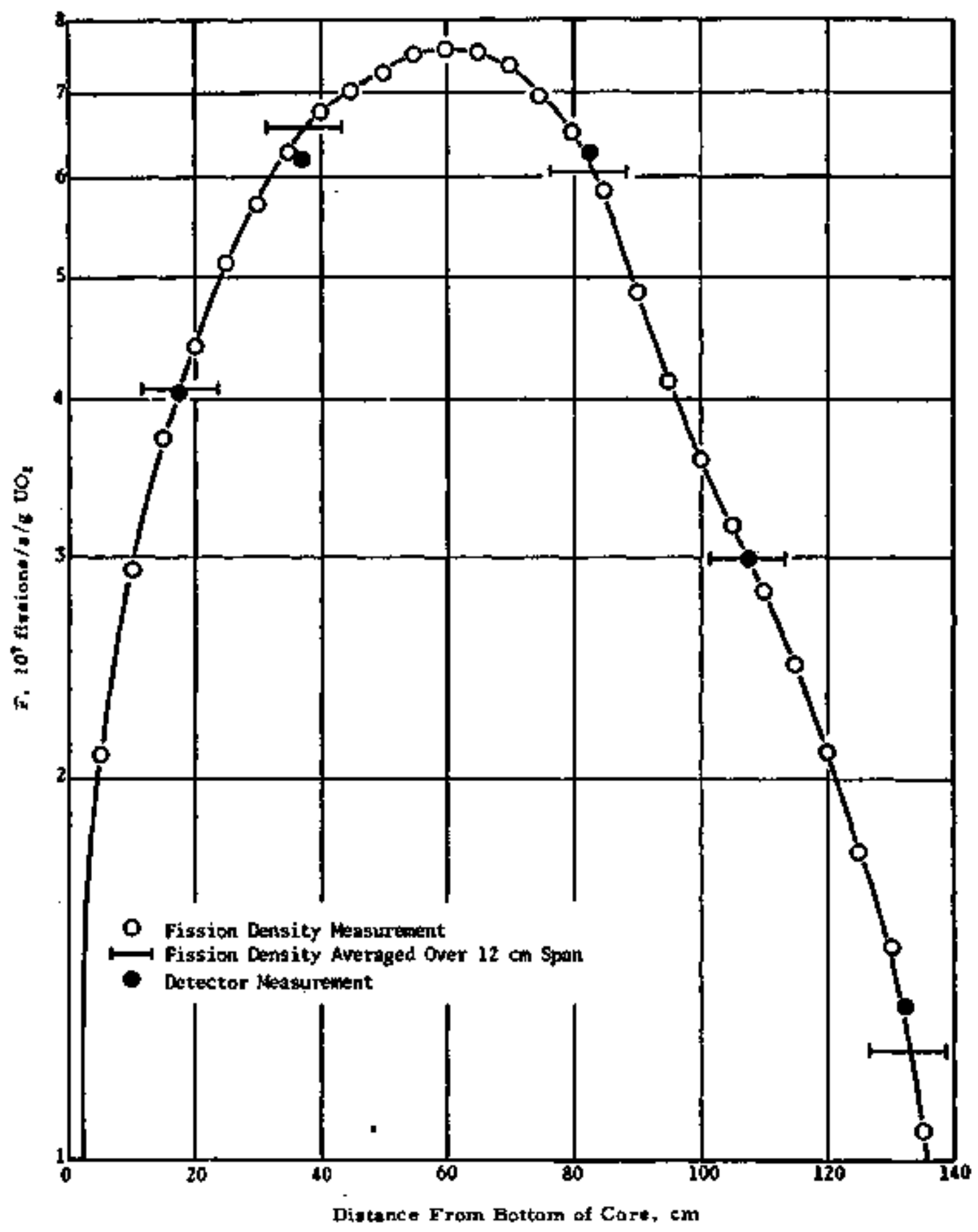


Figure 11. Relative Filation Power V. Distence From Core Bottom With Ag-In-Cd Pin Fully Withdrawn

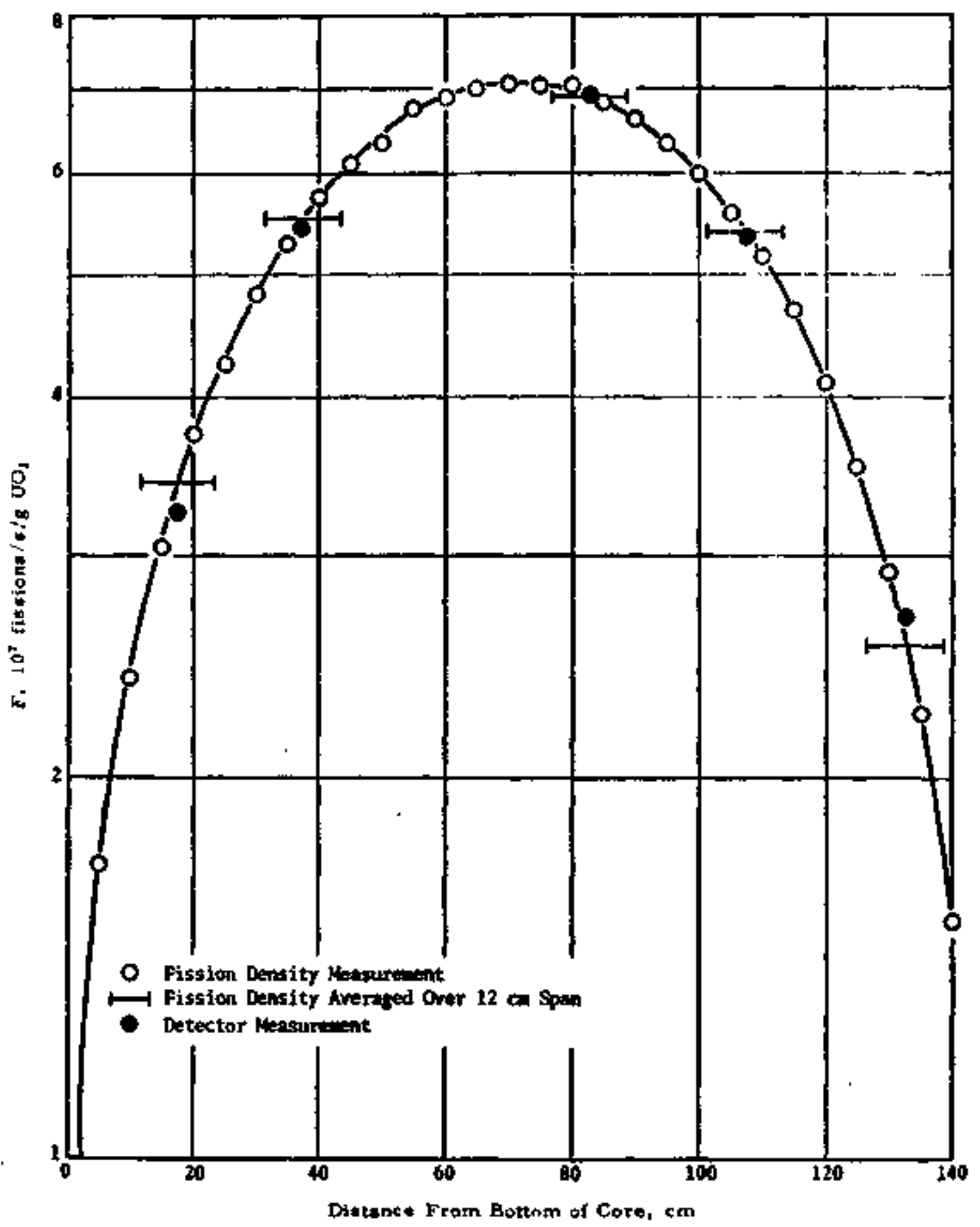


Figure 12. Reactor Mockup

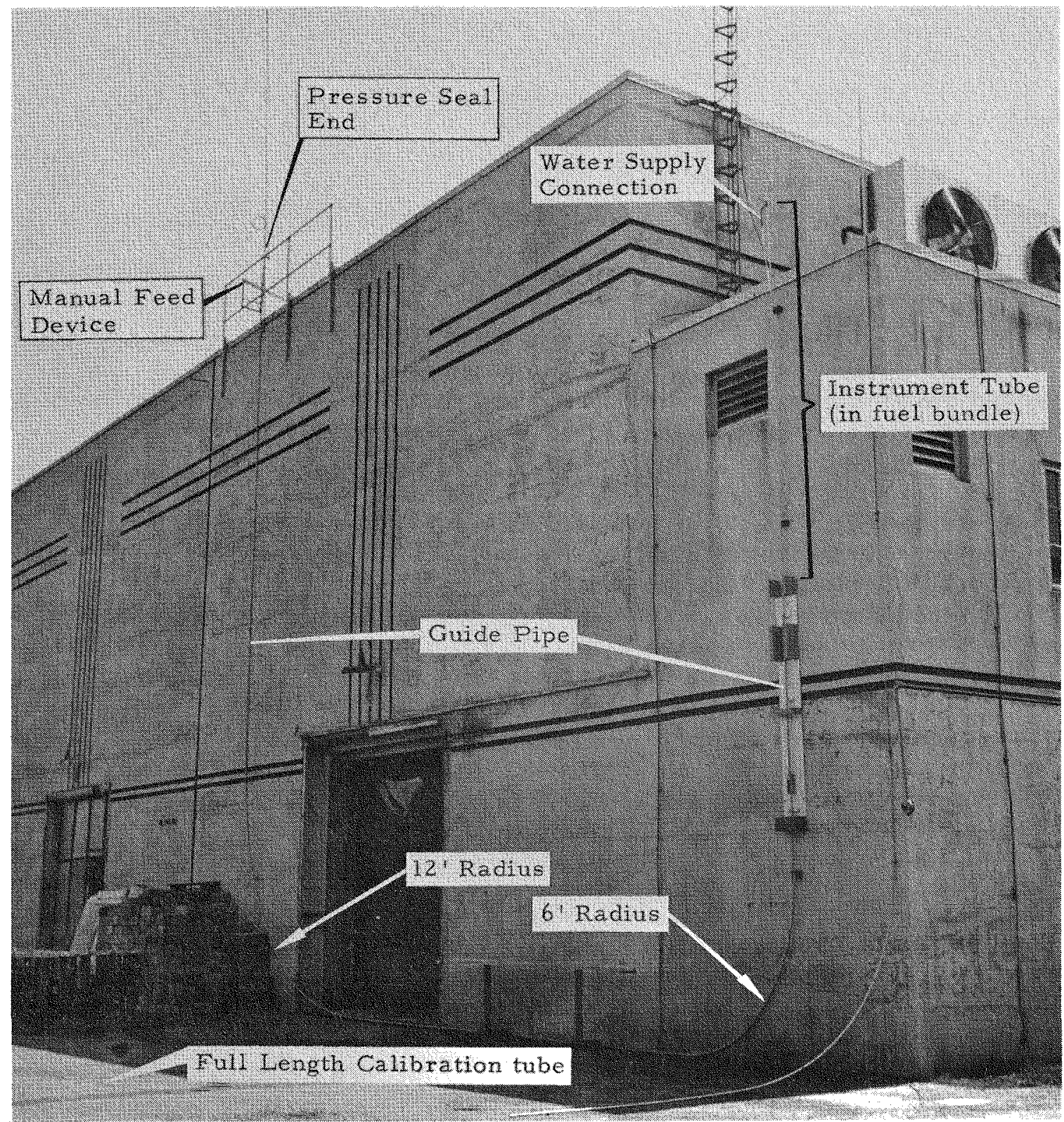


Figure 13. Big Rock Foint Detectur 5 Lifetime Teat

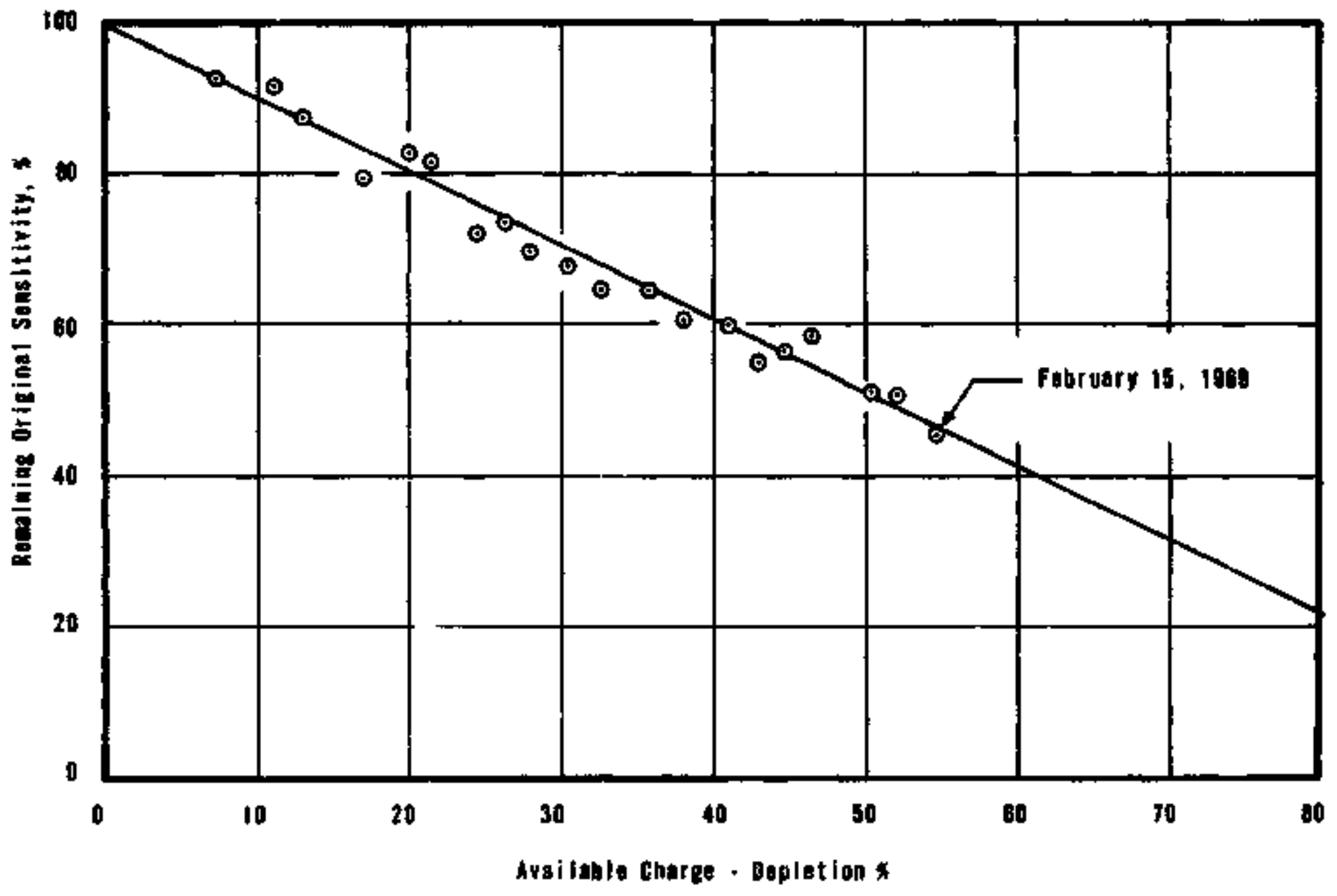


Figure 14. BAWTR Detector 7750 Lifetime Teat

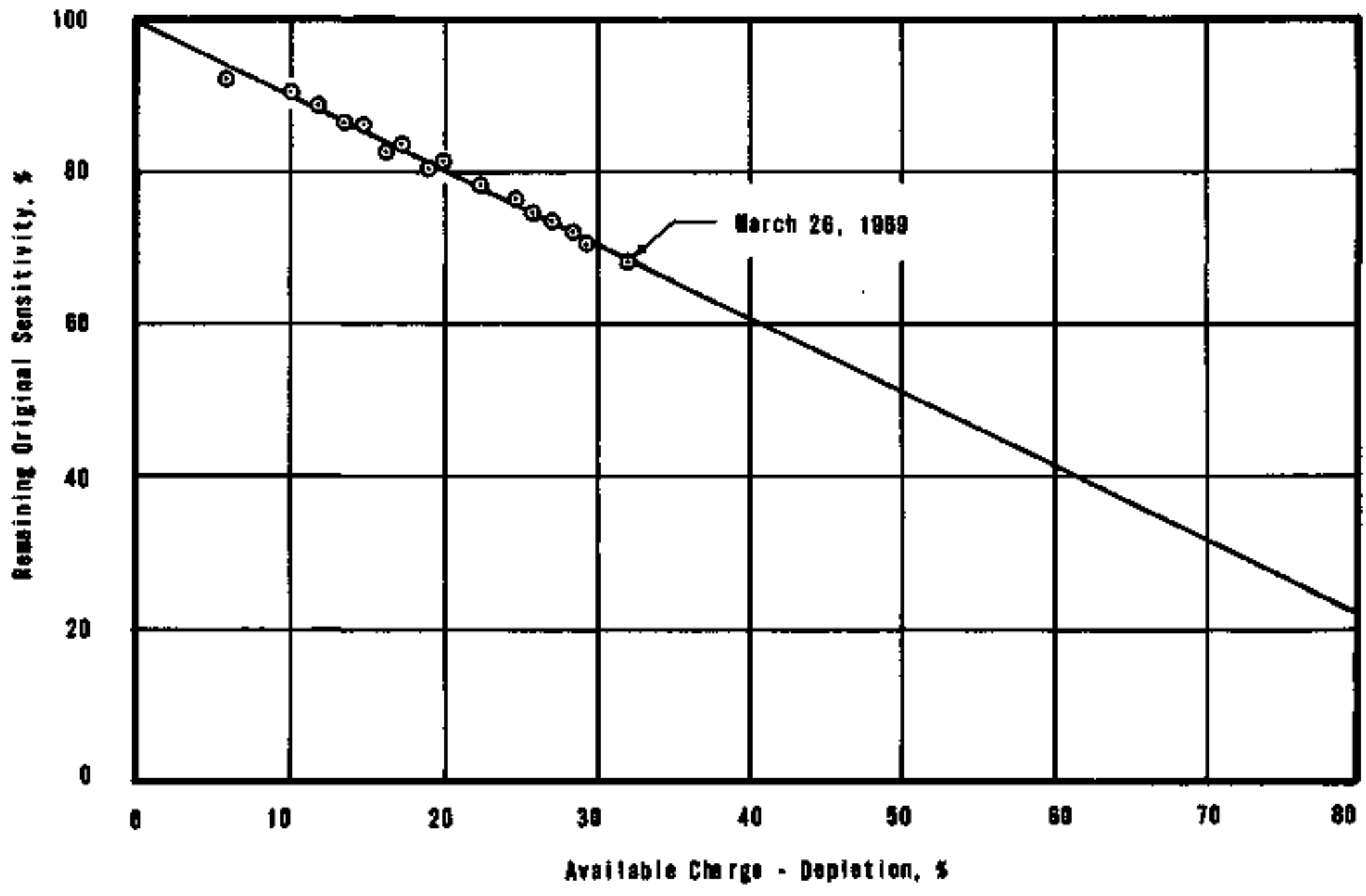


Figure 15. Big Rock Polnt Detector Data With Wire Scan Curve $(3-20-67)$

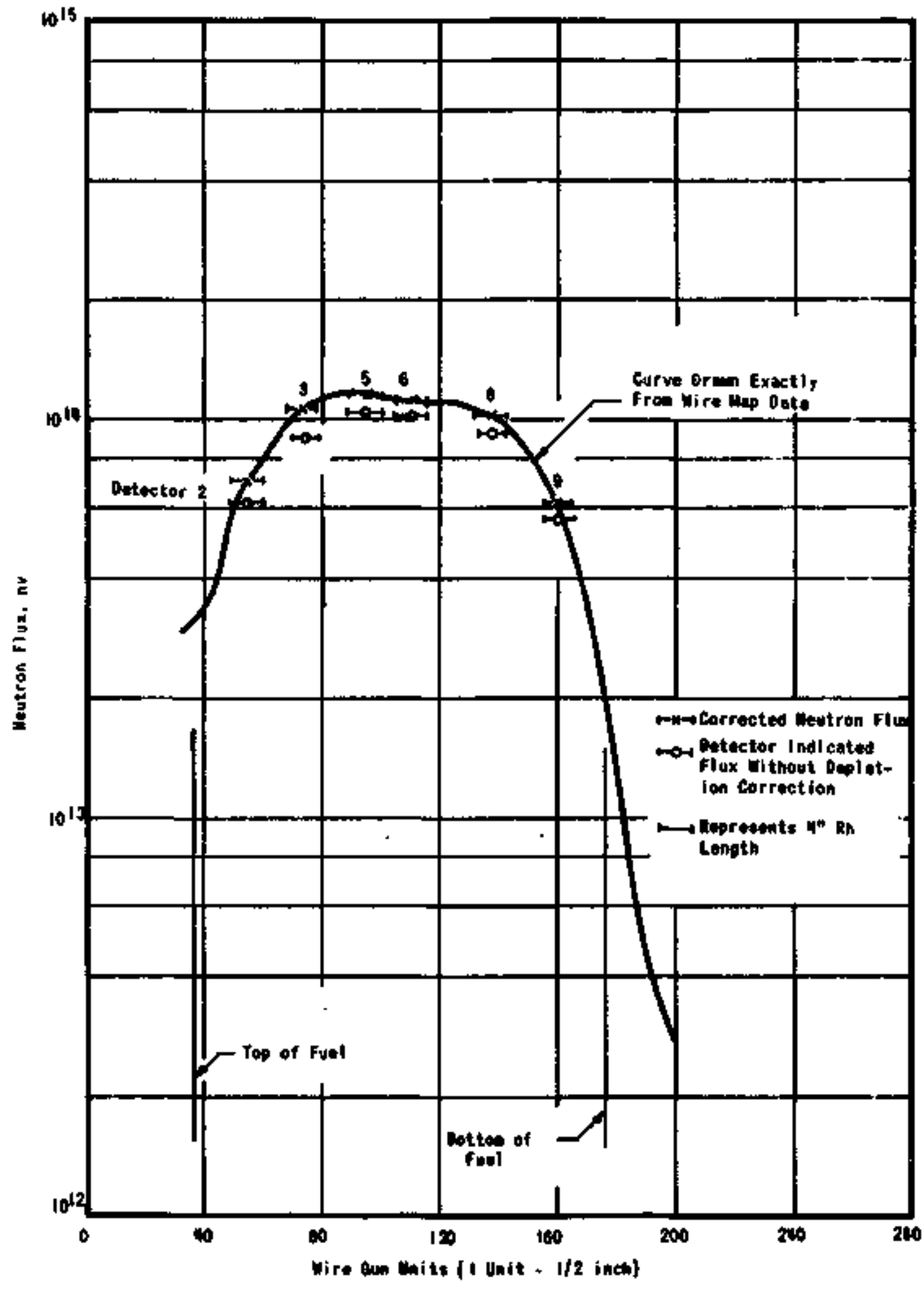


Figure 16. Big Rock Point Detector Data With Wire Scan Curve (11-2-67)

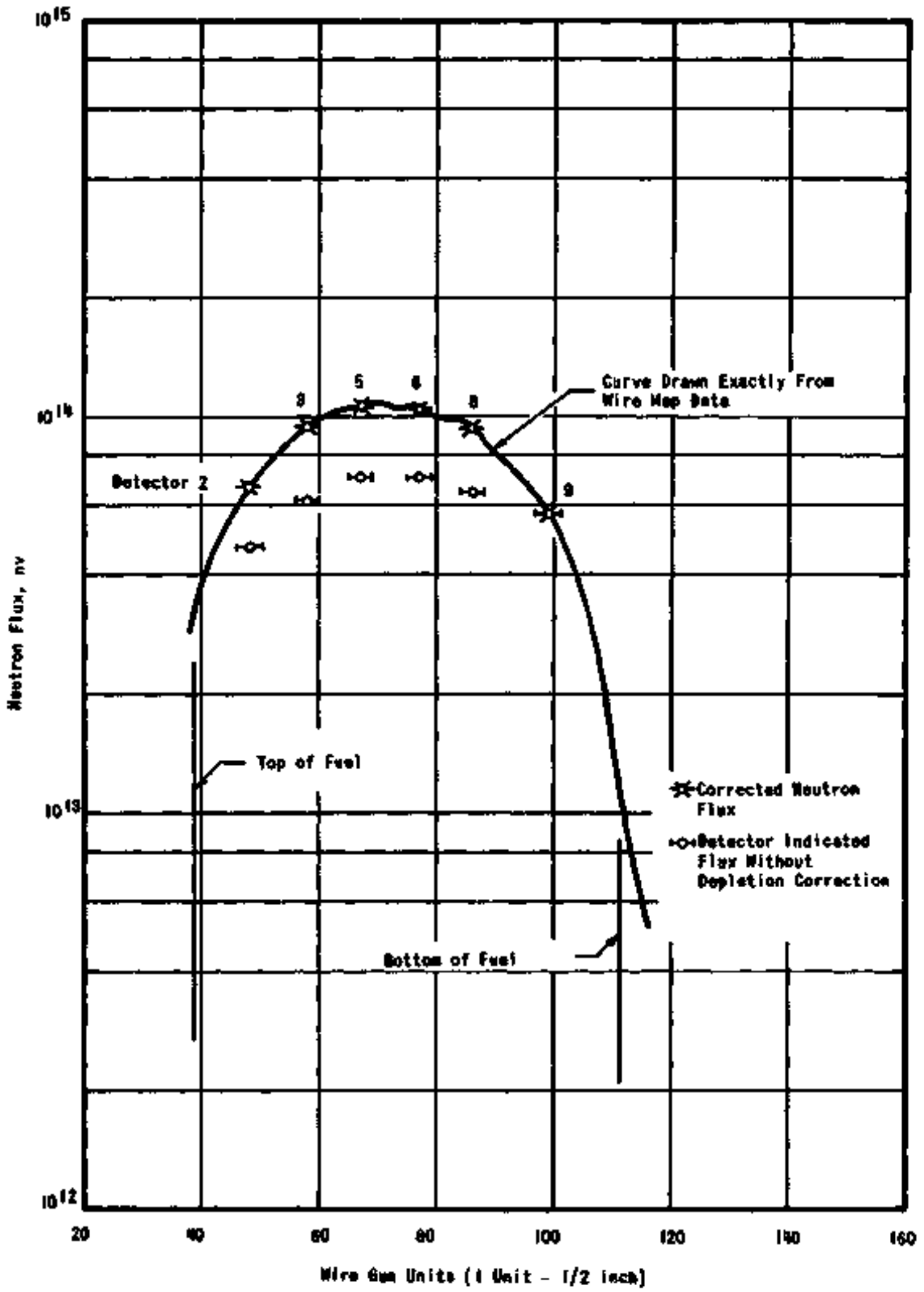


Figure 17, Big Rock Point Detector Data With Wire Scan Curve (6-10-68)

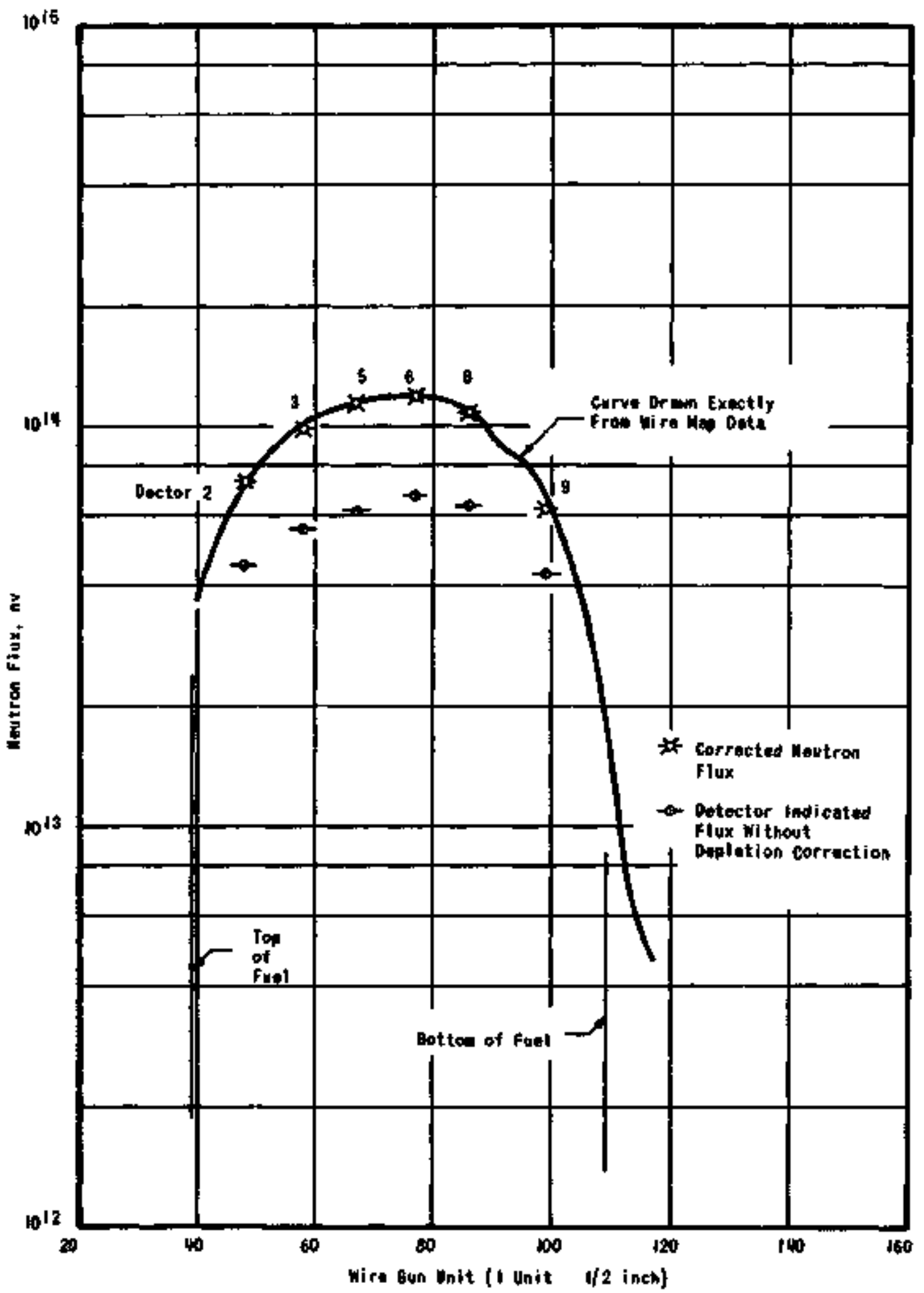


Figure 18. Big Rock Polnt Detector Date With Wire Scan Curve $(1-29-69)$

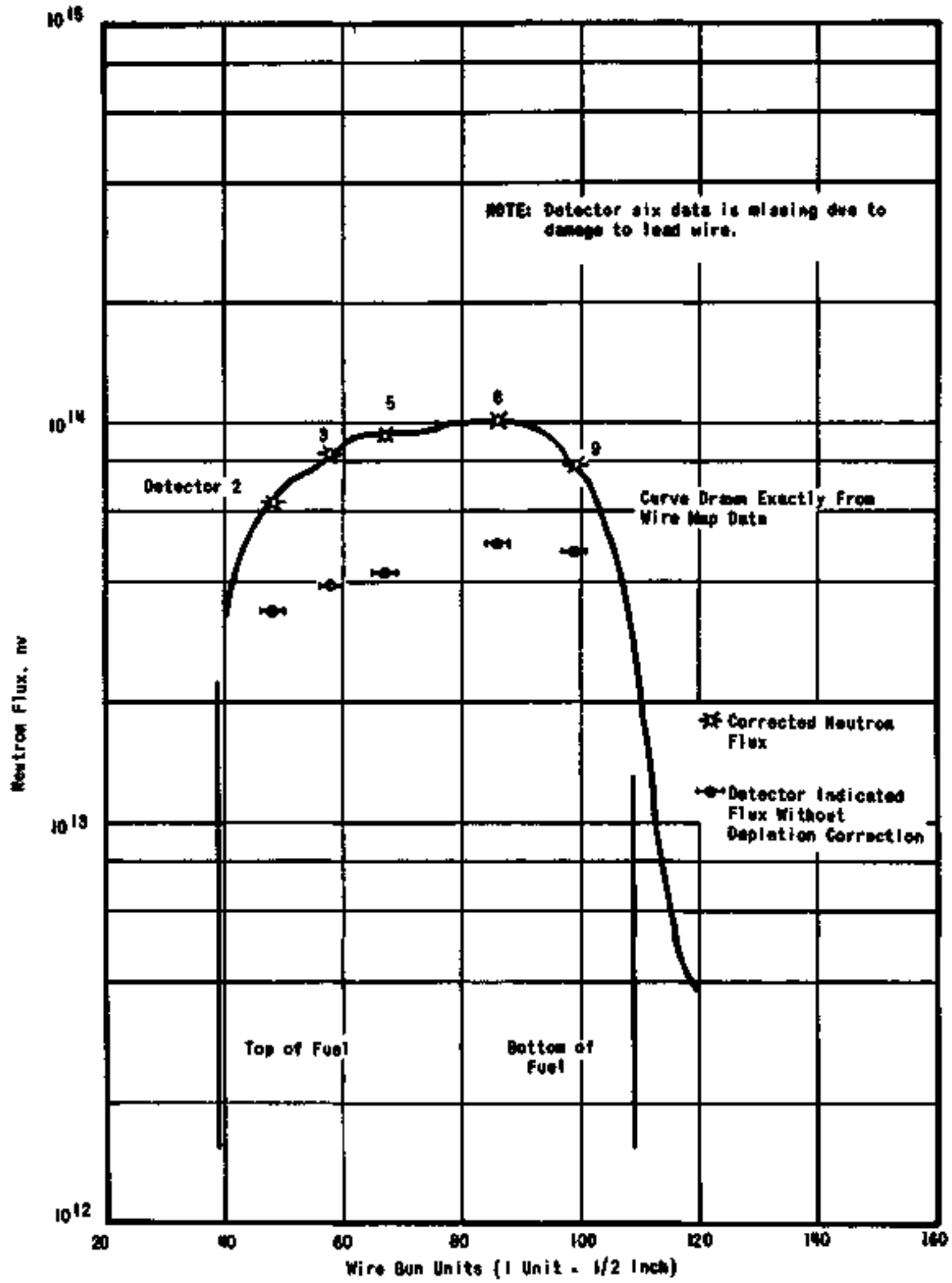

